\title{
PRIMACENES: novel non-cytotoxic primaquine-ferrocene conjugates with anti-Pneumocystis carinii activity $\dagger$
}

\author{
Joana Matos, ${ }^{a b}$ Nuno Vale, ${ }^{a b}$ Margaret S. Collins, ${ }^{c d}$ Jiri Gut, ${ }^{e}$ Philip J. Rosenthal, ${ }^{e}$ Melanie T. Cushion, ${ }^{c d}$ \\ Rui Moreira ${ }^{f}$ and Paula Gomes*ab
}

\author{
Received 17th June 2010, Accepted 21st June 2010 \\ DOI: 10.1039/c0md00082e
}

Primacenes, novel ferrocene-primaquine conjugates, were synthesized and screened for their antimalarial and anti-pneumocystis activity. Primacenes obtained by coupling primaquine amino acid derivatives to ferrocenoic acid were significantly active against Pneumocystis carinii and devoid of cytotoxicity, thus being more selective than the parent drug.

Primaquine (PQ, 1 in Scheme 1) is an antimalarial drug with potent gametocytocidal and modest blood-schizontocidal activity, against which no clinically relevant resistance has been associated to date, as the few PQ-tolerant strains of Plasmodium vivax that were so far identified were considered as most likely to present a priori differences regarding their sensitivity to PQ than true development of resistance to the drug. ${ }^{1} \mathrm{PQ}$ is also useful for the treatment of Pneumocystis infections ${ }^{1-4}$ caused by Pneumocystis jirovecii (formerly $P$. carinii $f$. $s p$. hominis ${ }^{2,3}$ ), which is a common cause of pneumonia in immunocompromised individuals and frequently the first serious illness encountered by HIV-infected patients. ${ }^{4-8} P$. jirovecii also infects other immunocompromised individuals such as those undergoing cancer therapy and organ and bone marrow transplants. ${ }^{9}$ The mechanisms by which PQ exerts its activity against either of these two pathogens are yet unveiled, ${ }^{1,4,10}$ but interference with electron transport in the respiratory chain, oxidative stress and impairment of mithocondrial function have been considered. ${ }^{\mathbf{1 , 1 0}}$

Ferrocene $(\mathrm{Fc})$ has been used in the preparation of bioactive organometallic structures, such as Fc-conjugates of peptides and nucleotides. ${ }^{11} \mathrm{Fc}$-conjugates of clinically relevant drugs have also been described as, for instance, arene isosteres in dopamine receptor ligands ${ }^{12}$ or organometallic antimalarials derived from 4-aminoquinolines. ${ }^{13}$ Indeed, the most emblematic example of the contribution of the $\mathrm{Fc}$ moiety to the improvement of a drug is that of Ferroquine (FQ), a chloroquine (CQ) isostere with an Fc-

${ }^{a}$ Centro de Investigação em Química, Universidade do Porto, R. do Campo Alegre,687,P-4169-007 Porto,Portugal.E-mail:pgomes@fc.up.pt; Fax. +351 220402659; Tel: +351 220402563

${ }^{b}$ Departamento de Química e Bioquímica, Faculdade de Ciências, Universidade do Porto, $R$. do Campo Alegre, 687, P-4169-007 Porto, Portugal.E-mail:pgomes@fc.up.pt; Fax: +351 220402659; Tel: +351 220402563

${ }^{c}$ Research Services, Veterans Affairs Medical Center, Cincinnati, OH, 45220, USA

${ }^{d}$ Division of Infectious Diseases, Department of Internal Medicine, University of Cincinnati, OH, 45267-0560, USA

${ }^{e}$ Department of Medicine, San Francisco General Hospital, University of California, CA, 94143-0811, USA

${ }^{f} i$ Med.UL, Faculdade de Farmácia, Universidade de Lisboa, Av. Professor Gama Pinto, P-1600-083 Lisboa, Portugal

$\dagger$ Electronic supplementary information (ESI) available: Detailed experimental procedures and chromatographic/spectroscopic data of novel compounds. See DOI: 10.1039/c0md00082e

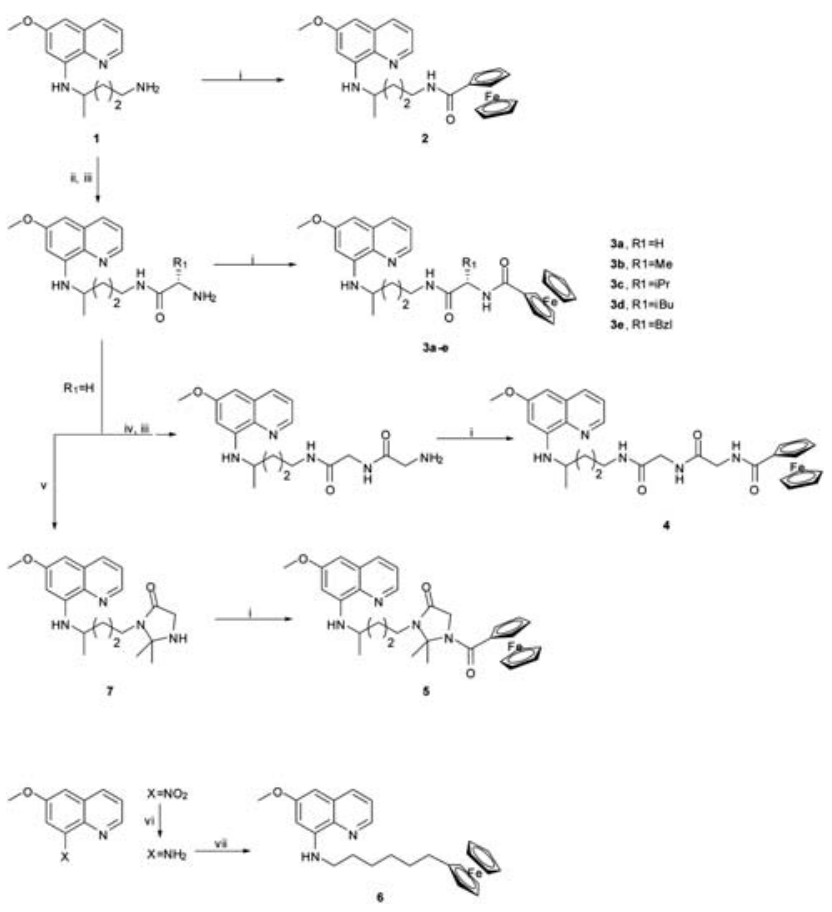

Scheme 1 Synthetic routes to Primacenes 2-6: (i) 1 eq. ferrocenecarboxylic acid, 1.1 eq. 1-ethyl-3-(3-dimethylaminopropyl)carbodiimide hydrochloride $(\mathrm{EDC} \cdot \mathrm{HCl}), 1.1$ eq. triethylamine $\left(\mathrm{Et}_{3} \mathrm{~N}\right)$, dry $\mathrm{CH}_{2} \mathrm{Cl}_{2}$, $90 \mathrm{~min}$ in ultra-sound bath (USB) at r.t.; (ii) 1.1 eq. $N^{\alpha}$-tert-butoxycarbonyl-protected amino acid $N$-hydroxy-succinimide ester (Boc $\mathrm{AA}_{1} \mathrm{OSu}$ ), 1.1 eq. $\mathrm{Et}_{3} \mathrm{~N}$, dry $\mathrm{CH}_{2} \mathrm{Cl}_{2}, 24 \mathrm{~h}$ at r.t.; (iii) neat $\mathrm{CF}_{3} \mathrm{COOH}, 30$ min at r.t., then drop-wise aq. $\mathrm{Na}_{2} \mathrm{CO}_{3}$ to $\mathrm{pH} 11$ followed by extraction with $\mathrm{CHCl}_{3}$; (iv) 1.1 eq. BocGlyOSu, dry $\mathrm{CH}_{2} \mathrm{Cl}_{2}, 24 \mathrm{~h}$ at r.t.; (v) dry propanone (2 eq. per day), 3 days in refluxing $\mathrm{CH}_{3} \mathrm{OH}$ with $4 \AA$ molecular sieves; (vi) 5 eq. $\mathrm{SnCl}_{2}$, dropwise conc. $\mathrm{HCl}, 24 \mathrm{~h}$ at r.t., then drop-wise aq. $8 \mathrm{M} \mathrm{NaOH}$ to $\mathrm{pH} 11$ followed by extraction with $\mathrm{CHCl}_{3}$; (vii) 1.5 eq. 6-bromo-hexylferrocene, $3.5 \mathrm{~h}$ in refluxing $\mathrm{Et}_{3} \mathrm{~N}$.

based side chain that is 22 times more potent than CQ itself and now under clinical trials. ${ }^{14,15} \mathrm{FQ}$ was found to, like $\mathrm{CQ}$, inhibit hemozoin formation ${ }^{14,15}$ but, remarkably, it is equally active against CQ-sensitive and CQ-resistant strains of both P. falciparum ${ }^{14,15}$ and P. vivax. ${ }^{16}$ This prompted Biot and coworkers to further investigate other mechanisms of action for FQ complementary to a CQ-like interference with hematin 
polymerization. ${ }^{15,17}$ These studies allowed important differences to be established between CQ and FQ in terms of basicity and lipophilicity, with FQ being 100 times more lipophilic than CQ at cytosolic $\mathrm{pH}$ and to be expectedly 50 -fold more concentrated than CQ at the putative acidic $\mathrm{pH}$ of the parasite's food vacuole (FV). ${ }^{15}$ This led to the assumption that FQ properties could be due to a highly efficient: (i) partition into, and/or hydrophobic collapse with, parasitic membrane lipids; (ii) concentration at the lipid site of hemozoin formation; (iii) maintenance of toxic hematin in the aqueous environment, by creating a barrier at the water-lipid interface. ${ }^{15}$ Additionally, the same research group found that under conditions mimicking the environment of the parasite's FV, FQ undergoes a Fenton-like redox reaction that generates highly reactive hydroxyl radicals known both to be rather pernicious towards membrane unsaturated fatty acids, and to promote chain reactions through peroxidation products. ${ }^{17}$ Such redox behaviour, which cannot be reproduced by CQ under similar conditions, possibly underlies the distinctive properties of FQ, not only concerning its blood-schizontocidal potency but also, and especially, its apparent lack of propensity to rapidly induce parasite resistance. ${ }^{15-17}$

The above findings have sprang a number of research studies where $\mathrm{Fc}$ was used to enhance the antimalarial activity of fluoroquinolones like ciprofloxacin, ${ }^{18}$ or to create novel dual-action hybrid drugs with highly promising results. ${ }^{19-22}$ In this connection, we hypothesized that insertion of the ferrocene core into either PQ or its derivatives might enhance their anti-plasmodial and anti-pneumocystis activities, mainly due to the redox properties of the Fc moiety.

Our previous research has been focused on Imidazoquines, a new class of imidazolidin-4-one peptidomimetic derivatives of PQ that display antimalarial and anti-pneumocystis activity while being resistant to premature metabolic inactivation by oxidative deamination. ${ }^{23-31}$ Thus, we have prepared a first generation of ferrocene-PQ conjugates (2-5) that we have called the Primacenes, by coupling ferrocenecarboxylic acid to amino groups present in PQ-based scaffolds (Scheme 1). We have also synthesized structure 6, a flexible ferrocene derivative of 8-amino-6-methoxyquinoline (MAQ), the heteroaromatic core of PQ (Scheme 1). To the best of our knowledge, there is no precedent in the literature concerning the preparation and study of any kind of ferrocene-primaquine conjugates. Detailed procedures on compound synthesis, chromatographic and spectroscopic data as well as in vitro biological evaluation against $P$. falciparum and $P$. carinii are given in the ESI. $\dagger$

Table 1 summarizes in vitro data concerning the antimalarial and anti-pneumocystis activity of the first set of nine primacenes prepared. The table also includes data on the cytotoxicity of the four most active compounds against $P$. carinii, on A549 human lung fibroblast carcinoma and L2 rat lung epithelial cell lines. All assays were run in duplicate.

An immediately eye-catching observation is that, while ferrocenoylation of PQ and of its derivatives, including of Imidazoquine 7 (precursor of Primacene 5), is generally detrimental for blood-schizontocidal activity against the CQ-resistant $P$. falciparum strain $\mathrm{W} 2$, the same does not apply to the compounds' anti-Pneumocystis activity. Thus, all tested compounds, except for the parent drug PQ (1) and for the PQ-Leucine-Ferrocene conjugate (3d), had $\mathrm{IC}_{50}$ over $10 \mu \mathrm{M}$ against $P$. falciparum. Artemisinin, a potent blood-schizontocidal, was also included in the screening as a comparator, and displayed an $\mathrm{IC}_{50}$ of $6.06 \mathrm{nM}$.

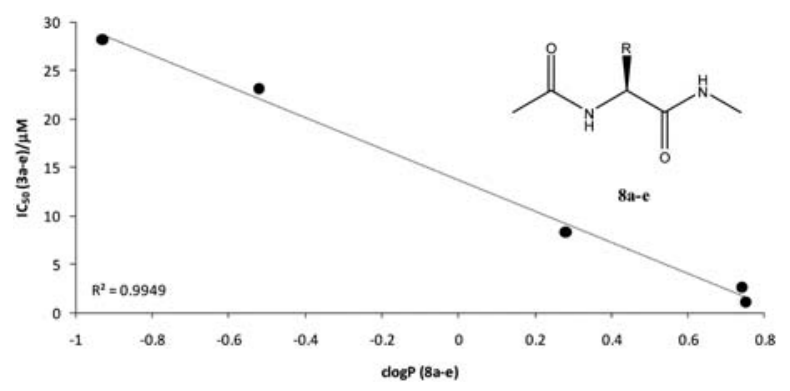

Fig. 1 Linear correlation found between $\mathrm{IC}_{50}$ values of Primacenes $3 a-e$ and $\operatorname{cog} \mathrm{P}$ values estimated (see Table 1) for model amides 8a-e.

Table 1 Cytotoxicity, anti-Pneumocystis activity and anti-Plasmodium activity of compounds 1-7

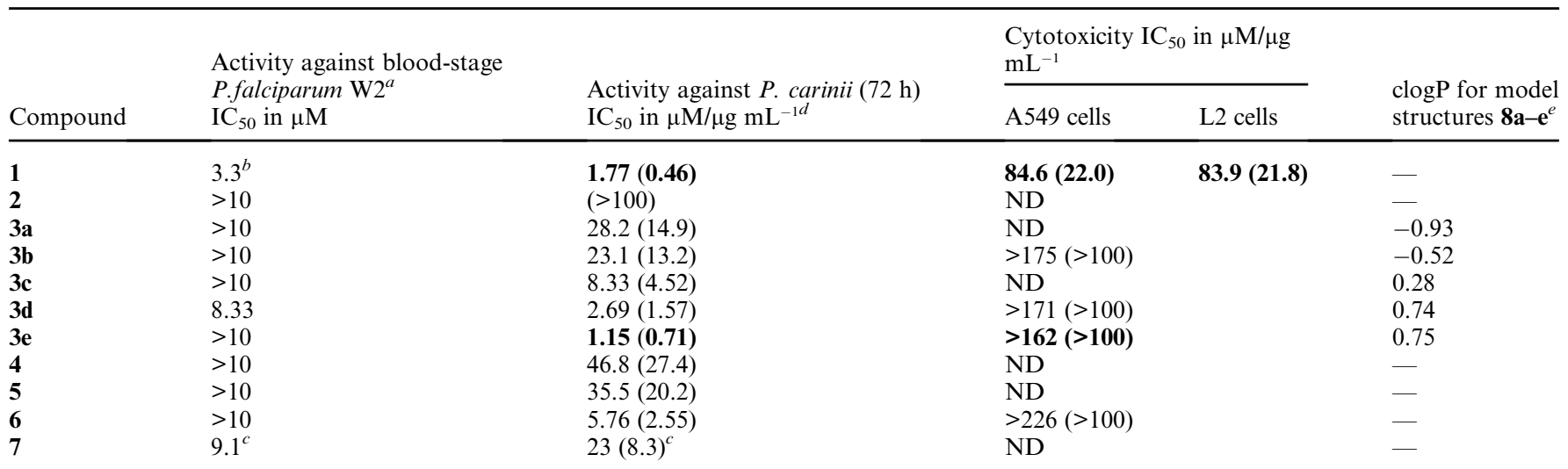

${ }^{a}$ CQ-resistant strain, against which highly active drugs have $\mathrm{IC}_{50} \mathrm{~s}$ at the low nanomolar range $\left[e . g ., \mathrm{IC}_{50}\right.$ for artemisinin $\left.=6.06 \mathrm{nM}\right] .{ }^{b} \mathrm{Taken}$ from ref. $23^{c}$ Taken from ref. $19^{d}$ Drug anti-Pneumocystis activity scale: highly active (compounds with an $\mathrm{IC}_{50}$ of $<0.010 \mu \mathrm{g} \mathrm{ml} \mathrm{l}^{-1}$ ), very marked $\left(\mathrm{IC}_{50} \mathrm{~s}\right.$ of 0.011 to $0.099 \mu \mathrm{g} \mathrm{ml}^{-1}$ ), marked ( $\mathrm{IC}_{50}$ s from 0.10 to $0.99 \mu \mathrm{g} \mathrm{ml}^{-1}$ ), moderate $\left(\mathrm{IC}_{50}\right.$ s from 1.0 to $\left.9.99 \mu \mathrm{g} \mathrm{ml}^{-1}\right)$, slight ( $\mathrm{IC}_{50} \mathrm{~s}$ from 10.0 to $49.9 \mu \mathrm{g} \mathrm{ml}{ }^{-1}$ ), and none (i.e., inactive; $\mathrm{IC}_{50} \mathrm{~S}$ of $\geq 50 \mu \mathrm{g} \mathrm{ml}{ }^{-1}$ ); ${ }^{32}$ Calculated using the OSIRIS Property Explorer (http://www.organic-chemistry.org/prog/peo/); ND, not determined. 
In turn, ferrocenoylation was almost never deleterious for antiPneumocystis activity, whose levels depended on the specific compound: while direct ferrocenoylation of PQ, as in 2, deleted the marked activity of the parent drug, the presence of an amino acid residue between the PQ moiety and the ferrocene core (3a-e) preserved activity, which was higher for more lipophilic structures (i.e., derived from amino acids leucine, 3d, and phenylalanine, 3e). Considering clog $\mathrm{P}$ values for the series of model amides $\mathbf{8 a}-\mathbf{e}$, which reflect the same amino acid variation as on primacenes $\mathbf{3 a}-\mathbf{e}$, we find a very good linear correlation between $\mathrm{IC}_{50}$ (3a-e) values and $\operatorname{cog} \mathbf{P}(\mathbf{8 a}-\mathbf{e})$ values (Fig. 1).

Overall, we found that, on a molar basis, primacene $3 \mathbf{e}$ was the best anti-Pneumocystis agent of the set, being even more active than PQ. In addition, neither 3e nor the other three most active primacenes (3c, $\mathbf{3 d}$ and $\mathbf{6})$ were cytotoxic against any of the two cell lines used $\left(\mathrm{IC}_{50}>100 \mu \mathrm{g} \mathrm{mL} \mathrm{mL}^{-1}\right)$, in clear contrast with the parent drug ( $\mathrm{IC}_{50} c a .22 \mu \mathrm{g} \mathrm{mL} \mathrm{m}^{-1}$ in both cases).

Finally, it should be mentioned that the distinct performance of primacenes as blood-schizontocidals $v s$. anti-pneumocystis agents was quite surprising, since our previous findings with PQ derivatives drove us to the assumption that there was a certain degree of correlation between these two types of bioactivity. ${ }^{27,31}$

At the present stage, we believe that the deletion of bloodschizontocidal activity caused by ferrocen(o)ylation of PQ derivatives or of MAQ is due to the fact that the final primacene structures lack a basic amine. The relevance of such a group has been proposed earlier ${ }^{33}$ and confirmed by our previous studies with PQ peptide and peptidomimetic (imidazoquine) derivatives. $^{23-31}$ To check this hypothesis, we are now working on the synthesis and in vitro evaluation of second-generation primacenes bearing basic amino groups.

\section{Concluding remarks}

Novel primaquine-ferrocene conjugates, the Primacenes, have been prepared and screened for their anti-Plasmodium (bloodstage parasites) and anti-Pneumocystis activities. Primacenes were seen to be devoid of significant antimalarial action, but one subset was found to be moderately to markedly active against Pneumocystis carinii. This subset included one compound, 3e, that was more active and markedly less cytotoxic than the parent drug, which is an unparalleled finding for PQ-based anti-Pneumocystis agents. Also, to the best of our knowledge, there is no precedent in the literature concerning the study of primaquineferrocene conjugates.

\section{Acknowledgements}

Thanks are due to FCT (Portugal) and FEDER (European Union) for funding this project (ref. PTDC/QUI/65142/2008 and FCOMP-01-0124-FEDER-007418). NV thanks FCT for a PostDoctoral grant (ref. SFRH/BPD/48345/2008).

\section{Notes and references}

1 N. Vale, R. Moreira and P. Gomes, Eur. J. Med. Chem., 2009, 44, 937 and references therein.
2 S. A. Readhead, M. T. Cushion, J. K. Frenkel and J. R. Stringer, J. Eukaryotic Microbiol., 2006, 53, 2.

3 D. L. Hanwksworth, Lancet Infect. Dis., 2007, 7, 3.

4 C. F. Thomas Jr. and A. H. Limper, Nat. Rev. Microbiol., 2007, 5, 298.

5 G. R. Seage, E. Losina, S. J. Goldie, A. D. Paltiel, A. D. Kimmel and K. A. Freedberg, J. Acquired Immune Defic. Syndr., 2002, 30, 421.

6 A. Morris, J. D. Lundgren, H. Masur, P. D. Walzer, D. L. Hanson, T. Frederick, L. Huang, C. B. Beard and J. E. Kaplan, Emerg. Infect. Dis., 2004, 10, 1713.

7 C. F. Thomas Jr. and A. H. Limper, N. Engl. J. Med., 2004, 350, 2487.

8 J. C. Peters.on and M. T. Cushion, Curr. Opin. Microbiol., 2005, 8, 393.

9 J. A. Fishman, Antimicrob. Agents Chemother., 1998, 42, 995.

10 S. F. Queener, J. Med. Chem., 1995, 38, 4739.

11 H.-B. Kraatz, J. Inorg. Organomet. Polym. Mater., 2005, 15, 83.

12 D. Huber, H. Hubner and P. Gmeiner, J. Med. Chem., 2009, 52, 6860.

13 M. A. L. Blackie, P. Beagley, K. Chibale, C. Clarkson, J. R. Moss and P. J. J. Smith, J. Organomet. Chem., 2003, 688, 144.

14 W. Daher, C. Biot, T. Fandeur, H. Jouin, L. Pelinski, E. Viscogliosi, L. Fraisse, B. Pradines, J. Brocard, J. Khalife and D. Dive, Malar. J., 2006, 5, 11 and references therein.

15 F. Dubar, J. Khalife, J. Brocard, D. Dive and C. Biot, Molecules, 2008, 13, 2900 and references therein.

16 M. L. Leimanis, A. Jaidee, K. Sriprawat, S. Kaewpongsri, R. Suwanarusk, M. Barends, A. P. Phyo, B. Russel, L. Renia and F. Nosten, Antimicrob. Agents Chemother., 2010, 54, 2228.

17 N. Chavain, H. Vezin, D. Dive, N. Touati, J.-F. Paul, E. Buisine and C. Biot, Mol. Pharmaceutics, 2008, 5, 710.

18 F. Dubar, G. Anquetin, B. Pradines, D. Dive, J. Khalife and C. Biot, J. Med. Chem., 2009, 52, 7954.

19 F. Bellot, F. Coslédan, L. Vendier, J. Brocard, B. Meunier and A. Robert, J. Med. Chem., 2010, 53, 4103.

20 N. Chavain, E. Davioud-Charvet, X. Trivelli, L. Mbeki, M. Rottmann, R. Brun and C. Biot, Bioorg. Med. Chem., 2009, 17, 8048 .

21 J. Manosroi, K. Rueanto, K. Boonpisuttinant, W. Manosroi, C. Biot, H. Akazawa, T. Akihisa, W. Issarangporn and A. Manosroi, J. Med. Chem., 2010, 53, 3937.

22 N. I. Wenzel, N. Chavain, Y. Wang, W. Friebolin, L. Maes, B. Pradines, M. Lanzer, V. Yardley, R. Brun, C. Herold-Mende, C. Biot, K. Tóth and E. Davioud-Charvet, J. Med. Chem., 2010, 53, 3214.

23 P. Gomes, M. J. Araújo, M. Rodrigues, N. Vale, Z. Azevedo, J. Iley, P. Chambel, J. Morais and R. Moreira, Tetrahedron, 2004, 60, 5551.

24 M. J. Araújo, J. Bom, R. Capela, C. Casimiro, P. Chambel, P. Gomes, J. Iley, F. Lopes, J. Morais, R. Moreira, E. de Oliveira, V. do Rosário and N. Vale, J. Med. Chem., 2005, 48, 888.

25 P. Chambel, R. Capela, F. Lopes, J. Iley, J. Morais, L. Gouveia, J. R. B. Gomes, P. Gomes and R. Moreira, Tetrahedron, 2006, 62, 9883.

26 R. Ferraz, J. R. B. Gomes, E. de Oliveira, R. Moreira and P. Gomes, J. Org. Chem., 2007, 72, 4189.

27 N. Vale, M. S. Collins, J. Gut, R. Ferraz, P. J. Rosenthal, M. T. Cushion, R. Moreira and P. Gomes, Bioorg. Med. Chem. Lett., 2008, 18, 485.

28 N. Vale, J. Matos, J. Gut, F. Nogueira, V. do Rosário, P. J. Rosenthal, R. Moreira and P. Gomes, Bioorg. Med. Chem. Lett., 2008, 18, 4150.

29 N. Vale, J. Matos, R. Moreira and P. Gomes, Tetrahedron, 2008, 64, 11144.

30 N. Vale, L. Gouveia, R. Moreira and P. Gomes, Eur. J. Med. Chem., 2009, 44, 2506.

31 N. Vale, M. Prudêncio, C. A. Marques, M. S. Collins, J. Gut, F. Nogueira, J. Matos, P. J. Rosenthal, M. T. Cushion, V. do Rosário, M. M. Mota, R. Moreira and P. Gomes, J. Med. Chem., 2009, 52, 7800 .

32 M. T. Cushion, F. Chen and N. A. Kloepfer, Antimicrob. Agents Chemother., 1997, 41, 379.

33 M. J. Portela, R. Moreira, E. Valente, L. Constantino, J. Iley, J. Pinto, R. Rosa, P. Cravo and V. do Rosário, Pharm. Res., 1999, 16, 949. 